analecta polit. | Vol. 9 | No. 17 | PP. 277-298 | julio-diciembre | 2019 | ISSN-e: 2390-0067 (en línea) |

Medellín-Colombia

doi: http://dx.doi.org/10.18566/apolit.v9n17.a05

Cómo citar

este artículo en APA: Pachón Soto, D. (2019).

El buen vivir como racionalidad económica alternativa. Analecta Política, 9(17), 277-298.

Fecha de recepción: 29.10.2018

Fecha de aceptación: 21.10 .2019

\section{El buen vivir como racionalidad económica alternativa $^{1}$}

Good living as an alternative economic rationality

Viver bem como racionalidade econômica alternativa

DAMIÁN PACHÓN SOTO

Doctor en Filosofía

Universidad Industrial de Santander

Correo electrónico: dpachons@uis.edu.co

1 El artículo de reflexión forma parte del Grupo de Investigación Población, Ambiente y Desarrollo, Categoría A1, de la Universidad Industrial de Santander.

The reflection article is part of the Population, Environment and Development Research Group, Category A1, of Universidad Industrial de Santander. 


\section{Resumen}

El presente artículo se propone, primero, analizar el concepto de razón, proponiendo el buen vivir/ vivir bien como una racionalidad alternativa y una manera especial de entender y proyectarse en el mundo; en un segundo momento, analiza la cosmovisión indígena resaltando su concepto holístico de la vida junto con su visión de la naturaleza.

Se analizan el principio de relacionalidad como alternativa a la visión sustancialista del mundo y, finalmente, se postula una economía vital al servicio de la vida humana. Se argumenta que la economía para la vida derivada del buen vivir funge como una alternativa a la racionalidad capitalista, pues ayuda a mitigar muchos de sus efectos nocivos.

Finalmente, se presentan algunas de las tensiones prácticas de la propuesta, las cuales dificultan su aplicación en el mundo de hoy. Estos objetivos se realizan revisando parte de las investigaciones sobre esta nueva cosmovisión y cotejándola con los principios de la lógica capitalista, para así arribar a una propuesta donde sea posible un equilibrio vitalista entre naturaleza y economía.

Palabras clave: buen vivir; vivir bien; cosmovisión; naturaleza; racionalidad; economía para la vida.

\section{Abstract}

Firstly, this article seeks to analyze the concept of reason by proposing good living / living well as an alternative rationality and as a special way of understanding and projecting oneself in the world. Secondly, it examines the indigenous worldview by highlighting its holistic concept of life along with its vision of nature.

The principle of relationality is analyzed as an alternative to the substantialist view of the world and, finally, a vital economy is postulated at the service of human life. It is argued that the economy for life derived from good living operates as an alternative to capitalist rationality, as it helps mitigate many of its harmful effects.

Finally, some of the practical tensions of the proposal are presented, which hinder their application in today's world. Part of the current research on this new worldview is reviewed and compared with the principles of capitalist logic. Thus, we arrive at a proposal where a vital balance between nature and economy is possible

Keywords: good living; living well; worldview; nature; rationality; economy for life. 


\section{Resumo}

Este artigo propôe-se, em primeira instância, fazer uma análise do conceito de ração, propondo o fato de viver bem como uma racionalidade alternativa, e uma maneira especial de entender e se projetar no mundo; numa segunda instância, analisa-se a cosmovisão indígena dando realce ao conceito holístico da vida, assim como sua visão da natureza.

Analisa-se o princípio de relacionalidade como alternativa para a visão substancialista do mundo e, finalmente, postula-se uma economia vital ao serviço da vida humana. Argumenta-se que a economia para a vida derivada do "viver bem" atua como uma alternativa à racionalidade capitalista, já que ajuda com a mitigação dos efeitos nocivos desta. Finalmente, apresentam-se algumas das tençóes práticas da proposta, as quais dificultam sua aplicaçáo no mundo atual. Estes objetivos são realizados com a revisão de uma parte das pesquisas ao respeito desta nova cosmovisão, comparando-as com os princípios da logica capitalista, para chegar a uma proposta onde possa ser possível um equilíbrio vitalista entre natureza e economia.

Palavra-chave: boa vida; viver bem; cosmovisão; natureza; racionalidade; Economia para a vida. 
Es precisamente porque otros posibles han sido convertidos en imposibles que nos es tan difícil imaginar otros reales. (Escobar, 2018, p. 14)

Siempre hay una estrecha conexión entre la realidad social, los marcos teóricos que utilizamos para interpretarla, y el sentido de política y esperanza que emerge de tal aproximación. (Escobar, 2012, p. 147)

\section{Introducción}

El buen vivir/vivir bien es una corriente de pensamiento emergente en América Latina surgida a partir de la cosmovisión indígena quechua y aimara. Su institucionalización se ha dado, especialmente, en las constituciones ecuatoriana y boliviana durante los gobiernos de Rafael Correa y Evo Morales. En la actualidad, se presenta como un pensamiento alternativo a la racionalidad occidental que separa sujeto/objeto, ser humano/naturaleza, y que le apuesta a un desarrollo como producto de un progreso indefinido. En realidad, esta corriente emerge como respuesta a la crisis capitalista, respuesta que se ofrece desde una circunstancia concreta: los valores culturales propios; como pensamiento situado, consciente del locus de enunciación y de las implicaciones geopolíticas del conocimiento; una corriente atenta a la especificidad histórica de la realidad, sus problemas y sus retos.

En este artículo, se realizará una discusión sobre el problema de la racionalidad y se argumentará por qué la racionalidad del buen vivir/vivir bien es alternativa. En un segundo momento, se pondrá de presente su cosmovisión, su concepción de la vida y la naturaleza, para, finalmente, mostrar cómo a partir de ella es posible postular una economía para la vida diferente de la noción económica actual. En las conclusiones, se ofrecen algunas de las tensiones de la propuesta que obstaculizan su aplicación práctica.

\section{Una racionalidad alternativa}

El ser humano es un producto tardío de la zoología, una especie de "corte" en la naturaleza y su magnífica diversidad. Ese "corte", es, más bien, un salto al "más allá" de la physis, un salto más allá de la mera naturaleza. Por eso, puede afirmarse, sin duda, que el ser humano es un ser meta-físico, porque gracias al pensamiento, al nous, al espíritu, o como se lo quiera llamar, pudo ponerse frente al mundo, escapar en un alto grado a sus determinaciones, y a partir de ahí, labrarse un pro- 
yecto propio de vida. Ese proyecto propio ha tomado forma en la antropogénesis en los mitos, en la filosofía, en la ciencia, en la técnica, en el arte, en la literatura, en el derecho, en el Estado, y en todo aquello que el humano ha producido. En este sentido, el ser humano es trascendente, pues, al no estar sometido totalmente a la legalidad de la physis, está en un constante proceso de construcción de su ser, a diferencia del animal que nace con el ser completo. Por eso, el ser humano es un ser en continuo nacimiento.

Ahora, ¿cómo pudo el ser humano, el Homo sapiens, que alcanzó cierto desarrollo cerebral, proyectarse sobre la naturaleza, tomarla como objeto de sus designios y labrar sobre ella? Es claro que con la razón: esa facultad que define en gran parte (no totalmente) lo que es ser ser humano. Sin ella, la autoconstitución de lo humano, su antropoiesis, no hubiera sido posible (Pachón, 2013). La razón fue el instrumento, la herramienta, que posibilitó ese "corte" y con ella la administración de la naturaleza; sin ella, y sin su capacidad proyectora, previsora y planificadora, el ser humano no se habría proyectado sobre la physis, ni habría podido llegar a ser lo que es.

¿Qué es, entonces, la razón? ¿Qué es este poder tan importante? Es una de las facultades humanas, junto con la memoria, la imaginación, la intuición. Es, también, tan solo una parte del ser humano, pues este es mucho más complejo, y está constituido por pasiones, instintos, inconsciente y, como decía Nietzsche, voluntad de poder. En este sentido, la razón tiene su especificidad dentro del vasto y complejo cúmulo de cualidades que es el humano.

Si nos atenemos a los aportes de la antropología cultural, de la sociología y de la etnografía, aparece algo innegable: todas las culturas se las arreglan de distintas maneras frente al mundo, tienen modos, maneras, formas, caminos, etc., muy variados de solucionar sus problemas y de producir y reproducir su vida, su comunidad; presentan una variada gama de estrategias para organizar su vida productiva, cultural y política. Y estos distintos modos son racionales. En la naturaleza, cada especie solo tiene preinscrita genéticamente —-más el aprendizaje respectivo - una manera de sobrevivir. En contraste, en el mundo humano, la diversidad cultural es prueba de la gran variedad de maneras de proyectarse y de estar en el mundo. El mito es una de esas formas racionales, es producto del logos, pues no se conocen mamíferos que tengan mitos. De ahí que la división occidental entre mito y razón es realmente falsa e ingenua. Esas racionalidades son formas de tratar con lo real, de otorgarle un sentido a su mundo, a cada ente, y al puesto del ser humano dentro del cosmos. El ser humano, pues, ha transformado y configurado el mundo que le interesa, le ha dado forma al mismo y estas modifi- 
caciones se adoptan cuando son útiles a la vida. Por lo pronto, y según lo anterior, se puede decir que la "facultad razón" es una, pero tiene múltiples modalidades. Estas modalidades son las "racionalidades", en plural.

En estricto sentido, podemos decir que en la cultura occidental la "racionalidad es un cierto modo de concebir la realidad, una manera característica de interpretar la experiencia vivencial, un modo integral de entender los fenómenos, un esquema de pensar, una forma de conceptualizar nuestra vivencia, un modelo (paradeigma) de (re)-presentar el mundo" (Estermann, 2006, p. 100).

Esta definición tiene sus homólogos en otras culturas. De ahí que en la diversidad cultural es posible encontrar "otras modalidades de la razón". Por eso, guardando las especificidades, podemos decir que la racionalidad es "un patrón de pensamiento y acción", un parámetro, un canon, una guía para la orientación y la actividad sobre el mundo. La razón también es histórica y se concreta como síntesis cultural, que se alimenta de la experiencia vital y sus valoraciones, pues, por ejemplo, el dominio de la naturaleza que se proponía en el siglo XVII como algo tan racional hoy no suena igual frente a la catástrofe ambiental que la producción humana ha causado. Lo que era racional en el siglo XVII no necesariamente es racional en el siglo XXI (Botero, 2005a, p. 28). La razón, es, entonces, "reguladora de las distintas formas de acción", pero también, en muchas culturas, como en la occidental, "previsora de las posibilidades históricas" (Botero, 2006, p. 62).

Se puede afirmar sin temor a equivocarse que toda cultura humana tiene patrones aceptados de interactuar con lo real, reglas para proyectarse al exterior y hacer determinadas cosas, maneras de concebir e interpretar los fenómenos, las valoraciones distintas de las prácticas, los "modelos" de interpretarse dentro del devenir del mundo, dentro de lo que es. Es decir, en este sentido, las racionalidades son presupuestos para producir y reproducir la vida de determinados grupos humanos. Estas racionalidades son ciertas "lógicas", maneras de actuar, comprender, valorar o proyectar.

Que la razón tiene modalidades es evidente cuando en la misma tradición occidental, ad intra, se habla de razón instrumental, razón formal, razón comunicativa, razón objetiva, razón subjetiva (Botero, 2006, pp. 34-60); igualmente, cuando se habla de razón libidinal, vital o poética (Pachón, 2011). Estas modalidades de razón en Occidente permiten también verificar la existencia de racionalidades o lógicas otras, ya sea la budista, la bantú o la racionalidad indígena o andina. En últimas, en todos estos casos, la racionalidad, si bien es social y la aprehendemos en el mundo de la vida al cual compare- 
cemos, es el a priori o el presupuesto del trato con lo real. Por eso, el reto es producir un acercamiento, un diálogo y un entendimiento entre esas distintas racionalidades; en pensar si son traducibles o inconmensurables.

\section{La cosmovisión del buen vivir/vivir bien}

Explicitar la manera como el buen vivir concibe la vida y la naturaleza requiere presentar algunos elementos importantes de la "racionalidad andina". En primer lugar, para el mundo indígena, no se trata de buscar la verdad, como aquello que está oculto y debe encontrarse o desvelarse mediante un esfuerzo cognoscitivo, tal como en la cultura occidental; más bien, en estas culturas, la realidad se presenta de manera simbólica, pues, antes que una representación abstracta, se busca una presentación misma de la realidad a través del culto y la ceremonia. Estos actúan como una especie de actualización y reinserción en la realidad misma: "El símbolo es la presentación de la realidad en forma muy densa, eficaz y hasta sagrada" (Estermann, 2006, p. 105); "el indígena toma la naturaleza como un objeto semiológico" (Botero, 2007, p. 114). Por ejemplo, la tierra no es un objeto que se trabaja, inerte, "sino un símbolo vivo y presente del círculo de la vida, de la fertilidad y retribución, del orden cósmico ético" (Estermann, 2006, p. 106). En estas culturas, "la realidad se revela como un conjunto holístico de símbolos significativos para la vida cotidiana” (p. 107), más que objetos desentrañados para ser manipulados.

En segundo lugar, antes que operar con el concepto de sustancia, como lo hace gran parte de la filosofía occidental, con excepción de Nietzsche o de Peter Sloterdijk, por ejemplo, las culturas andinas le apuestan a la relacionalidad. Mientras en Aristóteles la sustancia es la cosa individual, el ente único, conformado por la cópula materia y forma, donde esta última es lo fundamental, en las culturas andinas lo que existe son nudos o nodos, rizomas, conexiones, redes, vínculos. Es decir, no existe "algo" que luego se relaciona, sino que todo está previamente unido, ya que un ente totalmente separado sería una abstracción absoluta. Esto implica, también, que los accidentes no son cualidades, agregados de las cosas, ni productos de ellas, ni de su desenvolvimiento dialéctico. No. Forman parte ya del todo, de lo interrelacionado. Esta relacionalidad tiene un papel fundamental en la concepción antropológica, pues no hay individuo aislado, como mónada, tal como en la tradición liberal, sino que "el individuo como tal es un 'nada' (un no ente), es algo totalmente perdido si no se halla $[s i c]$ insertado en una red de múltiples relaciones" (p. 110). Esto quiere decir que la comunidad preexiste al individuo. 
De este principio de relacionalidad del todo, se desprenden tres subprincipios fundamentales para entender la cosmovisión andina. El primero de ellos es el de correspondencia, es decir, "que las regiones o campos de la realidad se corresponden de una manera armoniosa", por ejemplo, macro- y microcosmos, "tal en lo grande como en lo pequeño", "hay correspondencia entre lo cósmico y humano, lo humano y lo no-humano, lo orgánico e inorgánico, la vida y muerte, lo bueno y lo malo, lo divino y humano" (Estermann, 2006, p. 138). El segundo subprincipio es el de complementariedad, esto es, que cada cosa siempre tiene un complemento, co-existe con otro ente, solo el complemento hace pleno o completo a un determinado elemento. En este sentido, se supera la lógica excluyente occidental, pues, incluso, el opuesto es un complemento. Es, en realidad, como en la versión del ying y el yang, a saber, un pensamiento correlativo. El tercer y último subprincipio es la reciprocidad:

A cada acto corresponde como contribución complementaria un acto recíproco. Este principio no solo rige en las interrelaciones humanas (entre personas o grupos), sino en cada tipo de interacción, sea intra-humana, entre ser humano y naturaleza, o sea entre ser humano y lo divino [...] la ética no es un asunto limitado al ser humano y su actuar, sino que tiene dimensiones cósmicas. (Estermann, 2006, p. 145)

En tercer lugar, dejando de lado el principio de relacionalidad y continuando con la explicitación de la "racionalidad andina", hay que indicar que esta es no racionalista, es decir, es una modalidad distinta de la razón, donde la realidad no es aprendida mediante el "ver intelectual", teoría, o realidad atrapada en el concepto, sino que el acceso a ella se da a través de todos los sentidos, es más, se privilegian los accesos no visuales, tales como el tacto, el olfato o el oído. "Este último es la base para las diversas maneras mnemotécnicas de la tradición oral". De ahí que estas culturas tengan una racionalidad emocio-afectiva (Estermann, 2006, p. 114). Es, para decirlo con el filósofo colombiano Juan Cepeda, un "sentipensar ontológico" (2017).

En cuarto y último lugar, mientras en la cultura occidental la ciencia es concebida como un conjunto de proposiciones sobre la realidad, conocimiento que debe cumplir las características de la universalidad, necesidad, verificabilidad y repetibilidad, en las culturas andinas la ciencia (el saber) es:

El conjunto de la sabiduría (sophía) colectiva acumulada y transmitida a través de las generaciones. Existe un saber [...] del subconsciente colectivo, transmitido por procesos subterráneos de enseñanza de una generación a otra en forma oral 
y actitudinal ("saber hacer"), mediante narraciones, cuentos, rituales, actos cúlticos y costumbres. Este saber no es el resultado de un esfuerzo intelectual, sino el producto de una experiencia vivida amplia [...] se fundamenta sobre todo en el argumento de autoridad (el peso de los ancianos o yayaqkuna), de antigüedad (el peso de la tradición), de frecuencia (el peso de la costumbre) y de coherencia (el peso del orden). (Estermann, 2006, p. 119)

Esto da cabida a otras formas de conocer, formas que, desde luego, no son primitivas, precientíficas o premodernas. De lo que se trata es de comprender que la ciencia es solo una forma de trato con el mundo, y que, en este sentido, muchas culturas tienen maneras de asir lo real, y de emitir juicios, valoraciones, etc., diferentes sobre esta. Importa más que tales concepciones sean prácticas y que contribuyan a la producción, el desarrollo y la reproducción de la vida de los sujetos colectivos.

Explicadas brevemente estas notas de la racionalidad andina, es posible pasar a exponer su concepción de la vida y la naturaleza.

El buen vivir/vivir bien es también una filosofía andina de la vida. O mejor, una pachasofía o filosofía de la "pacha". Significa, según Macas (2010), "la vida en plenitud". La vida en excelencia material o espiritual. Esta vida plena se da, se realiza, en la "pacha", que como sustantivo quiere decir globo terráqueo, tierra, planeta, universo, "estratificación del cosmos", etc. Incluye no solo dimensiones espaciales (arriba, abajo, medio), sino también temporales (antes, después), pues todo se da en un lugar y en un tiempo. Incluye también la tempo-espacialidad de las almas, los espíritus, dioses, pues lo que se presenta es una "ontología reveladora de la comunión espiritual entre divinidades del cielo, terrenas o del inframundo, y los chamanes y líderes espirituales de las comunidades (Botero, 2007, p. 114).

Implica, desde luego, lo que llamamos naturaleza, por eso, en estricto sentido, pacha significa "cosmos interrelacionado" o "relacionalidad cósmica" (Estermann, 2006, pp. 155-158). Ese cosmos, orden, universo, mundo es una totalidad viviente, sin que esta categoría sea asumida de manera cerrada, ni dialéctica. La pachamama es, en la filosofía andina, sujeto. De Ahí que, en la Constitución Política de la República del Ecuador, la naturaleza sea sujeto de derechos (arts. 71-74). Este carácter de sujeto tiene importantes implicaciones que distancian la racionalidad andina de la raciomundanidad europea (Botero, 2005b). Como señala Botero (2007): "Nada en la naturaleza tiene para ellos el significado del mundo cósico, de una objetividad puesta para el uso caprichoso del hombre [...] La tierra no es un mero bien de producción sino algo sagrado" (p. 114). Si la 
naturaleza no es mundo cósico, si no ha sido desmagicalizada para ser dominada, esto quiere decir que se presenta en el buen vivir/vivir bien una superación del famoso dualismo occidental, cartesiano, sujeto/objeto, donde el ser humano está "aparte" de la naturaleza, y la toma como "cosa", y así crea una abstracción ingenua, pues el ser humano se "saca" con su espíritu del mundo natural y se pone en un más allá, desarraigado, desunido. El ser humano occidental se concibe como una mente flotante, un espíritu alado sin cuerpo, al decir de Schopenhauer, mientras que, en el mundo indígena, que no ha desencantado la physis, "los espíritus forman parte del mundo en que nos movemos, pueblan nuestro horizonte. No existe una espiritualidad separada del mundo material" (p. 115). Si la naturaleza no es algo exterior al ser humano, no puede ser concebida en el mundo andino como mercancía; no hay una relación instrumental con ella.

Pacari (2009) sostiene:

Según la cosmovisión indígena, todos los seres de la naturaleza están investidos de energía que es el SAMAI y, en consecuencia, son seres que tienen vida: una piedra, un río (agua), la montaña, el sol, las plantas, en fin, todos los seres tienen vida y ellos también disfrutan de una familia, de alegrías y tristezas al igual que el ser humano. (p. 33)

Por su parte, Choquehuanca (2010) afirma que el Suma Qamaña (vivir bien) es "recuperar la cultura de la vida y, recuperar nuestra vida en completa armonía y respeto mutuo con la madre naturaleza, con la Pacha Mama, donde todo es VIDA" (p. 10). En este sentido, "no hay nada separado". Y si todo es vida, "no hay muerte [...]. Aquí la muerte es otro momento de la vida porque se revive en las montañas o en las profundidades de los lagos o ríos" (Mamami, 2011, p. 69). Es en esta concepción, compleja, rica, variada, vitalizadora, en la que se materializan los principios de relacionalidad, complementariedad, equilibrio y reciprocidad (Ibáñez y Aguirre, 2013, p. 26).

Esta concepción del buen vivir resitúa al ser humano en la naturaleza. En estricto sentido, no puede hablarse de ser humano y naturaleza, sino del ser humano en y con la naturaleza, pues el humano está inserto, mora, habita, en la pachamama; no está separado de ella, intercambia energía con todos los seres vivos enlazados por el vínculo animista y energético del cosmos. En este sentido, se trata de un biocentrismo o un ecocentrismo holístico, en el que los flujos vitales circulan y vigorizan todo. Esta racionalidad es una superación del antropocentrismo moderno, surgido en el Renacimiento cuando el ser humano se empodera frente a la historia providencial, y se reconoce él mismo como protagonista de su 
futuro, de su destino. El antropocentrismo concibe al ser humano como causa eficiente de lo existente, como punto de origen, desligado de todo, y empoderado con la antorcha de la razón. Es el ser humano autónomo, libre, des-religado de los dioses, del cosmos, escindido en sí mismo y separado de la naturaleza. El antropocentrismo es una concepción que produjo lo que llamaré aquí "la cuádruple ruptura" del ser humano moderno.

\section{Hacia una economía para la vida}

La economía neoliberal es la nueva teología de la sociedad contemporánea. Es producto del desenvolvimiento paulatino de una razón profana que aceleró la historia a partir de 1070, cuando se invadió Jerusalén, y que originó como reacción las Cruzadas que, a partir de 1099, abrieron la vieja y estática cultura medieval a un ritmo nuevo: la forma vida-frenesí (Pachón, 2010, pp. 131-154).

Fueron la secularización de la razón, el antropocentrismo, el advenimiento del individualismo y la transformación de la sociedad feudoburguesa de los siglos XIV, XV y XVI los elementos que configuraron la sociedad capitalista, posible solo por el matrimonio del Estado con el capitalismo. Ya Max Weber mostró cómo el derecho romano y su asunción por el Estado contribuyeron a la racionalización que favoreció la nueva mentalidad económica. La burocracia y la profesionalización permitieron la administración de la nueva empresa, por eso, "desde el punto de vista de la sociología, el Estado moderno es una empresa con el mismo título que una fábrica: en esto consiste su rasgo histórico específico [...] La empresa capitalista moderna descansa ante todo en el cálculo" (Weber, 2004, p. 1061).

Desde luego, ese no fue un proceso inmanente de la historia europea. Fue posible gracias a los descubrimientos geográficos de los siglos XV y XVI, que posibilitaron la formación del sistema-mundo/moderno/colonial que permitió crear a nivel global un mapa jerárquico de los intercambios económicos, a la vez que brindó insumos para la consolidación de la modernidad. Por eso el colonialismo es la cara oscura del proceso moderno y elemento constitutivo de su subjetividad (Mignolo, 2007).

La economía capitalista que surgió de estos procesos está vinculada al colonialismo. No solo por la explotación de la mano de obra o la obtención de materias primas, sino por su paulatina expansión hegemónica asociada a la violencia, y gracias justamente a ese imperialismo. La economía capitalista como producto de 
la cultura europea fue imponiéndose sobre las culturales periféricas, aniquiló las propias formas productivas y las tachó de precapitalistas y premodernas, básicamente porque carecían de la racionalidad del cálculo y la acumulación. Esa economía contribuyó al "epistemicidio" de las cosmovisiones aborígenes y las sepultó bajo el manto del interés, el ahorro, la acumulación y la inversión perpetuas.

El capitalismo fue acuñado por el colonialismo, el individualismo racional abstracto, el encumbramiento de la razón instrumental secularizada (pensamiento de dominio al decir de Max Scheler), los valores ascéticos, el realismo práctico y el utilitarismo de los puritanos; la naciente ciencia puesta al servicio de la realización de objetivos prácticos (Merton, 2013, p. 693 y ss.). Igualmente, los logros del pensamiento científico y la técnica acrecentarían en la Ilustración esa racionalidad capitalista mediante la incorporación de la noción de progreso, que, al concebir lo nuevo como parte de un acrecentamiento ilimitado, formó filosofías de la historia optimistas, con un futuro abierto y de perfección para la humanidad. Como he sustentado en otro lado (Pachón, 2010), la idea filosófica del progreso fue la matriz que hizo posible la idea de desarrollo en el siglo XX. Ese progreso es la creencia en la perfectibilidad humana y en la realización posible de la felicidad material y espiritual aquí en la "ciudad terrena". Esa felicidad es, entre otras cosas, producto del dominio de la naturaleza, y de lo que Francis Bacon llamó, en 1620, "el imperio humano sobre el universo", dominio que "reside solamente en las artes y en las ciencias" (2011, p. 176).

¿Cuáles son las notas fundamentales de esa racionalidad capitalista? Pimentel (2016) las ha sintetizado así:

Esta racionalidad está orientada principalmente por el cálculo, la utilidad individual y las necesidades materiales, por eso la ganancia se considera como el fin más importante de la actividad económica y la vida en general [...] En el caso de la racionalidad económica instrumental, capitalista: a) hay una apropiación individual y privada de la riqueza; b) se busca reducir al máximo los costos de los recursos: la tierra y el trabajo; c) la producción se organiza de manera jerárquica (unos mandan y otros obedecen) y con una división del trabajo que promueve la enajenación y limita la creatividad —a menos que signifique un beneficio para el capitalista; d) el disfrute de los bienes producidos es solo para aquellos que mediante el mecanismo de los precios pueden adquirirlos; e) el consumo se limita a las necesidades materiales, sin atender las necesidades afectivas, identitarias y creativas, entre otras; y f) la naturaleza es algo exterior, son recursos susceptibles de ser explotados. (pp. 37-38) 
Aquí están condensadas las notas fundamentales de la racionalidad económica capitalista actual. Veamos ahora la crítica planteada a ese modelo por el buen vivir, crítica que no se comprende sin los presupuestos filosóficos esbozados atrás.

1. El buen vivir propone un modelo económico en construcción, en atención a los valores culturales diversos y, por tanto, como expresión de una racionalidad alternativa. En este sentido, esta nueva economía, esta racionalidad productiva, carece del concepto de progreso como perfectibilidad ilimitada en el tiempo futuro, así como de la noción de desarrollo basada en el crecimiento económico, entendido como el incremento de las exportaciones y la captación de la inversión extranjera. Como ha dicho Acosta (2014):

Lo que interesa aquí es que bajo algunos saberes indígenas no existe una idea análoga a la de desarrollo, lo que lleva a que en muchos casos se rechace esa idea. No existe la concepción de un proceso lineal de la vida que establezca un estado anterior y posterior, a saber, de subdesarrollo y desarrollo; dicotomía por la que deben transitar las personas para la consecución del bienestar, como ocurre en el mundo occidental. (p. 37)

Por eso, el buen vivir/vivir bien rechaza otras nociones como desarrollo alternativo y otras propuestas basadas en una supuesta humanización del capitalismo; al igual que todas aquellas atravesadas por posiciones economicistas.

2. Si la modernidad ha puesto la vida al servicio del capital y de la economía, el buen vivir pone la economía al servicio de la vida; la economía es un medio simplemente para vivir, no es un fin. Por eso, en esta concepción la economía depende de la cultura, de los valores culturales, y no es un campo autónomo, cerrado, desligado de la complejidad de la vida. Por eso, si la economía capitalista está caracterizada por la lógica del cálculo y la acumulación y la ganancia como fines primordiales, la economía del buen vivir es, más bien, una economía del equilibrio, que busca la armonía, la satisfacción de las necesidades básicas, y la posibilitación del ejercicio de las libertades, las capacidades, el goce y el disfrute de los derechos individuales y comunitarios. Es, como señala Ramírez (2010), "la consecución del florecimiento de todos y todas, en paz y armonía con la naturaleza y la prolongación indefinida de las culturas humanas", sin producir ningún tipo de dominación sobre otros (Gudynas y Acosta, s. f.). El fin (el telos) no es el aumento ilimitado de la tasa de ganancia o la acumulación, sino la producción, la reproducción y la potenciación de la vida, es decir, la búsqueda de lo que Botero (2005b) llamó la cosmovitalidad. 
3. Veamos lo anteriormente dicho en los dos casos paradigmáticos: Ecuador y Bolivia. En el caso de Ecuador, en el preámbulo de la Constitución de 2008, se dice:

NOSOTRAS Y NOSOTROS, el pueblo soberano del Ecuador

RECONOCIENDO nuestras raíces milenarias, forjadas por mujeres y hombres de distintos pueblos,

CELEBRANDO a la naturaleza, la Pacha Mama, de la que somos parte y que es vital para nuestra existencia,

INVOCANDO el nombre de Dios y reconociendo nuestras diversas formas de religiosidad y espiritualidad,

APELANDO a la sabiduría de todas las culturas que nos enriquecen como sociedad,

COMO HEREDEROS de las luchas sociales de liberación frente a todas las formas de dominación y colonialismo, y con un profundo compromiso con el presente y el futuro,

Decidimos construir

una nueva forma de convivencia ciudadana, en diversidad y armonía con la naturaleza, para alcanzar el buen vivir, el sumak kawsay.

Como puede observarse, además de explicitar el hecho de que se pretende "alcanzar el buen vivir, el sumak kawsay", desde el inicio se reconocen las "raíces milenarias" del pueblo ecuatoriano, se nombra directamente a la pachamama y se asumen las "diversas formas de religiosidad y espiritualidad", aspectos clave para el buen vivir (o vivir bien).

Hay que resaltar que la Constitución alude a los derechos del buen vivir, en el título 2, capítulo 2. Allí se encuentran los derechos al agua, la alimentación, el ambiente sano, la educación, la vivienda, la cultura, la ciencia, etc. El artículo 14 dice:

Se reconoce el derecho de la población a vivir en un ambiente sano y ecológicamente equilibrado, que garantice la sostenibilidad y el buen vivir, sumak kawsay.

Se declara de interés público la preservación del ambiente, la conservación de los ecosistemas, la biodiversidad y la integridad del patrimonio genético del país, la prevención del dańo ambiental y la recuperación de los espacios naturales degradados.

Estas disposiciones están complementadas en el artículo 275 que alude al régimen del desarrollo. Este es definido como 
el conjunto organizado, sostenible y dinámico de los sistemas económicos, políticos, socio-culturales y ambientales, que garantizan la realización del buen vivir, del sumak kawsay. El Estado planificará el desarrollo del país para garantizar el ejercicio de los derechos, la consecución de los objetivos del régimen de desarrollo y los principios consagrados en la Constitución. La planificación propiciará la equidad social y territorial, promoverá la concertación, y será participativa, descentralizada, desconcentrada y transparente. El buen vivir requerirá que las personas, comunidades, pueblos y nacionalidades gocen efectivamente de sus derechos, y ejerzan responsabilidades en el marco de la interculturalidad, del respeto a sus diversidades, y de la convivencia armónica con la naturaleza.

Lo interesante de esta definición de desarrollo es que articula todas las dimensiones de la sociedad: lo político, lo económico, lo cultural, lo ambiental, etc., y que, al cotejarlo con el artículo 14, permite deducir que la naturaleza está por encima del mercado y del logro de los objetivos económicos, pues se alude a un "ambiente sano", al equilibrio ecológico, a la prevención del daño ambiental y a la recuperación de los espacios naturales. Igualmente, incluye la participación de los actores en la definición de este y recalca la soberanía alimentaria, económica y energética.

Esta constitución contempla el buen vivir como derechos, los cuales, en el constitucionalismo moderno, implica que deben tener aplicación inmediata, pues vinculan las políticas y las actuaciones del Estado y sus autoridades públicas. Igualmente, estos derechos deben verse de manera integral, interdependientes y con igual jerarquía, lo cual significa un gran avance en términos de ingeniería constitucional.

4. Por su parte en la Constitución Política del Estado Plurinacional de Bolivia, promulgada por el presidente Evo Morales el 7 de febrero de 2009, desde su preámbulo se habla de la plurinacionalidad, se alude a las luchas anticoloniales, se nombra directamente a la pachamama y se asume el objetivo de la superación del "Estado colonial, republicano y neoliberal". Y ya en el capítulo sobre "Principios, valores y fines del Estado", en el artículo 8, se dice:

I. El Estado asume y promueve como principios ético-morales de la sociedad plural: ama qhilla, ama llulla, ama suwa (no seas flojo, no seas mentiroso ni seas ladrón), suma qamaña (vivir bien), ńandereko (vida armoniosa), teko kavi (vida buena), ivi maraei (tierra sin mal) y qhapaj ñan (camino o vida noble). II. El Estado se sustenta en los valores de unidad, igualdad, inclusión, dignidad, libertad, solidaridad, reciprocidad, respeto, complementariedad, armo- 
nía, transparencia, equilibrio, igualdad de oportunidades, equidad social y de género en la participación, bienestar común, responsabilidad, justicia social, distribución y redistribución de los productos y bienes sociales, para vivir bien.

A diferencia de la Constitución ecuatoriana, en esta el vivir bien aparece como principios, valores y fines del Estado, es decir, no aparecen como derechos, lo que les da una menor definición y alcance. Por lo demás, en esta carta, hay una mayor amplitud cultural, pues se asumen principios de las culturas quechua, aimara y guaraní, vinculados con el modelo de Estado y con la búsqueda de la igualdad, la inclusión, la justicia social y el bien común. Esto es claro en el artículo 306, en el que se dice: "El modelo económico boliviano es plural y está orientado a mejorar la calidad de vida y vivir bien". Con todo, en el artículo 313, como afirman Gudynas y Acosta (s. f.): "Se insiste en que para lograr el vivir bien en sus múltiples dimensiones, la organización económica debe atender a propósitos como generación de producto social, redistribución justa de la riqueza, industrializar los recursos naturales".

Aquí se presenta una ruptura con la principialística esbozada, pues "industrializar los recursos naturales" implica el regreso a una concepción de la naturaleza como una canasta de recursos que deben ser transformados y usados. De hecho, este tipo de formulaciones, un poco in abstracto, dejan la puerta abierta a interpretaciones que justifican prácticas económicas antiambientales, no participativas, extractivistas, que pueden perjudicar a las comunidades. De hecho, esta es la denuncia de Rivera (2015), para quien el concepto vivir bien, en la práctica, le ha servido al Gobierno de Morales para reproducir los esquemas y las prácticas desarrollistas tradicionales en contravía de los derechos de la población indígena. Por eso, Rivera ha dicho que esta es una "palabra hueca".

Más adelante aludiré a algunas de las limitaciones del buen vivir/vivir bien. Por ahora, explicitemos otras características esenciales de esta alternativa al progreso, al desarrollo, y, como sostiene Gómez (2018), a la civilización, pues no es solo el modelo económico el que está en crisis, sino el modelo civilizatorio mismo, su forma de vida.

5. El buen vivir/vivir bien, al ser una concepción de lo "que es" holista, monista o una ontología relacional, en términos de Escobar (2018), implica un equilibrio entre el individuo y la comunidad; otorga gran importancia a los valores afectivos, solidarios, comunitarios, cooperativos, sobre los valores de la civilización egocéntrica. De ahí la importancia de la vida comunitaria en 
las culturas andinas, en las que las relaciones sociales no están regidas por la competencia y el "sálvese quien pueda". La comunidad es la condición de posibilidad de la realización vital, pues, ante todo, el ser humano es social, vive con otros, convive en relaciones mutuas necesarias. No hay solipsismo. Es la armonía del nosotros sobre el Yo, sin que esto implique desdibujar el individuo y su singularidad, ni fundamentar posiciones totalitarias. Es, más bien, un puente armónico, donde no se presenta una contradicción insalvable entre el individuo y sus intereses, y los intereses del colectivo, pues la comunidad aparece como el ámbito de la realización personal. En la vida social, entonces, prima la solidaridad frente a la competencia y el egoísmo. La solidaridad entendida como una "relación horizontal entre personas que constituyen un grupo, una asociación o comunidad, en condiciones de igualdad; es un vínculo que permanece en el tiempo y que obliga a los individuos del colectivo, con responsabilidades ante los demás" (Razeto, 2005, citado por Pimentel, 2016, p. 13).

7. La propiedad comunitaria es, entonces, un sustituto de la propiedad privada occidental, que, justamente, nace de privar a alguien de sus "medios de vida", como ya lo anotó Marx (1976) al hablar de la acumulación originaria del capital y su formación en Inglaterra. La propiedad privada es "acumulación por desposesión", como indica David Harvey. Sin embargo, el buen vivir/vivir bien no implica la abolición de la propiedad privada, sino que reconoce distintas formas de propiedad, entre ellas, la propiedad colectiva, así como reconoce distintas formas de producción.

8. Este sentido comunitario y colectivo refuerza los lazos de identidad histórica, con la tradición, las luchas, contrario a la movilidad de identidad y a la crisis de esta en la sociedad velocífera posmoderna. El ser humano no es una abeja sin panal, como en la sociedad occidental actual, sino que se reconoce dentro de una tradición con sus valores. Entre ellos, los valores económicos respectivos. Esto no implica una concepción esencialista de la identidad de las culturas y las comunidades, pues en esta utopía se le apuesta a la articulación de las comunidades y sus demandas, lo cual fortalece las luchas, es por ello, más bien, una filosofía intercultural (Cruz, 2016).

9. El buen vivir le apuesta a la re-comunalización de la sociedad. Esto ha llevado a pensadores como Santos (2010) a hablar del socialismo del buen vivir, en el que se resalta de la sociedad comunitaria el gobierno de lo común, donde la democracia es participación y las instituciones responden a la "gestión" del 
equilibrio holístico, la autonomía, el autogobierno, los reclamos de identidad colectiva, etc., principios relacionados con la inclusión social, política y económica, frente a las múltiples exclusiones del sistema capitalista actual.

10. El buen vivir no le apuesta al bienestar tradicional, ni a los estándares de calidad de vida del sistema capitalista. En este sentido, son más factibles otras opciones, por ejemplo, el esquema de las necesidades de Max-Nee (2006): "subsistencia, protección, afecto, entendimiento, participación, ocio, creación, identidad, libertad" (pp. 73-75); y la coordinación económica entre las comunidades locales, los grupos descalzos y el Estado (Pachón, 2006). Igualmente, aboga por una economía que tiene que diversificar la producción y defender los intereses de los pequeños Estados, pues la monoproducción favorece la dependencia y el colonialismo.

El buen vivir/vivir bien, al margen de las distintas versiones y usos que se le han dado al concepto en la lucha por instaurar su significado (Gudynas, 2014, p. 82 y ss.), es una apuesta que rechaza toda filosofía de la historia y, por ende, la noción de progreso y desarrollo en sus versiones eurocéntricas y occidentales; pone en primer lugar la vida, la naturaleza y la comunidad, y le apuesta a la relacionalidad cósmica. Es, por eso, una concepción biocéntrica y cosmocéntrica, que supera el antropocentrismo, y que recoge valores como la solidaridad, la ayuda, la cooperación, como maneras de favorecer lo que Botero (2005b) llama la cosmovitalidad latinoamericana o lo que he llamado una "forma-vida-orgánica" (Pachón, 2010).

\section{Para concluir: algunas tensiones}

El buen vivir es una categoría en disputa. Es decir, es un significante vacío que intenta ser llenado u homogeneizado por diversos contenidos, con tal de propiciar la universalidad de este y lograr su aceptación en la sociedad. Justamente por eso es un concepto en construcción, objeto de la lucha política, que se puede convertir en una gran herramienta para la construcción de un mundo alternativo futuro.

Ahora, si bien el concepto tomó auge con el constitucionalismo ecuatoriano y boliviano, estos mismos gobiernos, en la práctica, han hecho distintos usos y, según algunas críticas, lo han desfigurado. Sostiene Zibechi (2015):

El mismo gobierno Correa, que proclama la revolución ciudadana, no solo sigue apostándole a la explotación petrolífera, sino que busca expandir la minería a cielo 
abierto, a lo que se opone el movimiento indígena que ha hecho marchas [...] En Bolivia, donde la suma Qamaña/vivir bien inspiró la cumbre de Cochabamba, se registra la misma contradicción ya que el gobierno de Evo sigue profundizando la explotación minera y los hidrocarburos como principal herramienta económica. (p. 283)

García (2017a) es plenamente consciente de esta tensión en el seno de lo que él llama el "socialismo comunitario del vivir bien" (p. 62). Y es probable que tal tensión no se resuelva pronto, pues el Estado necesita industrializarse y así obtener recursos, mientras se consolidan las instituciones y otras políticas para hacerlo posible. Para él, "la contradicción fundamental antagónica sigue siendo la de la unidad del pueblo boliviano enfrentado al imperialismo que se resiste a reconocer nuestra soberanía y capacidad de autodeterminación en la construcción de nuestro destino" (García, 2017b, p. 26).

Esta tensión general es importante, pues implica un enfrentamiento directo con el mercado, las grandes corporaciones, los intereses trasnacionales, en un clima ideológico de derechización y advenimiento del neofascismo, en el que, por lo regular, la rebeldía de los Estados progresistas es castiga por el sistema hegemónico, tal como sucedió en Grecia con el partido Syriza de Alexis Tsipras, donde la democracia fue convertida en rehén de las finanzas, cuyos intereses defienden la Unión Europea y el Banco Central Europeo. A la presión externa, se le suma las tensiones internas entre los intereses privados aún presentes en el Estado y el bienestar común, y entre la dinámica de los movimientos sociales, su autoorganización, horizontalidad, diversidad y flexibilidad frente a la jerarquía, la centralización y el orden exigidos por las instituciones estatales.

Estas tensiones se patentizan también cuando las mismas comunidades exigen la intervención del Estado con planes de desarrollo, muchas veces compatibles con proyectos mineros o extractivistas, e incompatibles con la filosofía del buen vivir/vivir.

Frente a las propuestas del buen vivir/vivir bien, caben varias preguntas: ¿cómo puede articularse con los movimientos sociales, los partidos políticos, etc., para convertirse en una concepción del mundo hegemónica, que dispute a nivel estatal el sentido común al neoliberalismo?, ¿cómo responde desde el punto de vista del desarrollo de las fuerzas productivas y a la necesidad de mantener una alta productividad dado el crecimiento demográfico actual, el cual tiende a incrementarse en los próximos años?, ¿cómo responde al desequilibrio entre la ciudad y el campo, frente al proceso actual de descampe- 
sinización y urbanización de las sociedades?, ¿cómo puede evaluarse la eficiencia de sus propuestas económicas?, ¿cómo se articula el buen vivir con los movimientos sociales antiglobalización, para que efectivamente se convierta en una alternativa al orden de vida capitalista mundial?, ¿quién y cómo se determina cuando se ha roto el equilibrio y la armonía entre la naturaleza y las intervenciones humanas sobre ella? y, finalmente, ¿no hay una romantización de la concepción que tenemos de las culturas andinas en torno a temas como el patriarcado, la relación ser humano/naturaleza y el conflicto? Estas son preguntas válidas en el actual contexto internacional, en el que el neofascismo parece ser el instrumento para la defensa del capital, y, tal vez, se anuncie un darwinismo social salvaje, en que el antagonismo entre los de arriba y los de abajo será fundamental para determinar la supervivencia en la tierra, en Gaia.

Para finalizar, es pertinente recordar con Escobar (2012) que "el desarrollo se ha basado exclusivamente en un sistema de conocimiento, es decir, el correspondiente al Occidente moderno. La predominancia de este sistema de conocimientos ha dictaminado el marginamiento y descalificación de los sistemas de conocimientos no occidentales" (p. 39).

Por esa misma razón, deben rescatarse otras epistemologías y otras prácticas políticas y culturales, para con ellas superar la "falacia desarrollista" (Dussel, 1994), en la que no queda más alternativa que seguir el camino de Europa y reproducir así su modelo tanato-político con todas las víctimas y desequilibrios generados. Por eso, el buen vivir debe verse como una utopía alternativa, una verdad inmadura pero en construcción, que puede movilizar sentido, afectos y que en el futuro puede alumbrar la praxis social y política. Recordemos que la utopía no es un imposible como suele decirse, un no lugar como se desprende de su etimología, sino que es producto de la imaginación creadora, que, en una operación de crítica de lo real, postula una distancia entre el mundo que tenemos y el deseo, y así crea otra versión de lo que puede ser.

\section{Referencias}

Acosta, A. (2014). El buen vivir más allá del desarrollo. En G. C. Delgado Ramos (Coord.), Buena vida, buen vivir: imaginarios alternativos para el bien común de la humanidad. (pp. 21-60). Ciudad de México, México: Universidad Nacional Autónoma de México.

Bacon, F. (2011). La gran restauración (Novum Organum). Madrid, España: Tecnos. Botero Uribe, D. (2005a). El derecho a la utopía. Bogotá, Colombia: Universidad Nacional de Colombia. 
Botero Uribe, D. (2005b). Si la naturaleza es sabia, el hombre no lo es. Bogotá, Colombia: Produmedios.

Botero Uribe, D. (2006). Discurso de la no razón. Bogotá, Colombia: Produmedios.

Botero Uribe, D. (2007). Vitalismo cósmico. Bogotá, Colombia: Corteza de Roble.

Cepeda, J. (2017). Sentipensar ontológico. Bogotá, Colombia: Autores Editores.

Choquehuanca Céspedes, D. (2010). Hacia la reconstrucción del vivir bien. Recuperado de http://www.plataformabuenvivir.com/wp-content/uploads/2012/07/ChoquehuancaReconstruccionVivirBien2010.pdf

La Asamblea Nacional Constituyente expide la presente Constitución Política de la República del Ecuador. Recuperado de http://pdba.georgetown.edu/Parties/Ecuador/Leyes/constitucion.pdf

Constitución Política del Estado Plurinacional de Bolivia. Recuperado de http://www.ftierra. org/index.php/generales/14-constitucion-politica-del-estado

Cruz, E. (2016). El buen vivir y la crítica del universalismo abstracto. Cuadernos de Filosofía Latinoamericana, 37(115), 177-198. Recuperado de https://revistas.usantotomas.edu.co/ index.php/cfla/article/view/2392

Dussel, E. (1994). 1492. El encubrimiento del otro: el origen del mito de la modernidad. La Paz, Bolivia: Plural Editores.

Escobar, A. (2012). Una minga para el posdesarrollo: lugar, medio ambiente y movimientos sociales en las transformaciones globales. Bogotá, Colombia: Desde abajo.

Escobar, A. (2018). Otro posible es posible: caminos hacia Abya Yala/afro/Latinoamérica. Bogotá, Colombia: Desde abajo.

Estermann, J. (2006). Filosofía andina: sabiduría indígena para un mundo nuevo. La Paz, Bolivia: Instituto Superior Ecuménico Andino de Teología.

Fukuyama, F. (1992). El fin de la historia y el último hombre. Bogotá, Colombia: Planeta.

García Linera, Á. (2017a). Socialismo comunitario: un horizonte de época. La Paz, Bolivia: Presidencia de la Asamblea Legislativa Plurinacional.

García Linera, Á. (2017b). Las tensiones creativas de la revolución: la quinta fase del proceso de cambio. La Paz, Bolivia: Presidencia de la Asamblea Legislativa Plurinacional.

Gómez Müller, A. (2018). El vivir bien, una crítica cultural del capitalismo. Ciencia Política, 13(25), 199-222. Recuperado de https://dialnet.unirioja.es/servlet/articulo?codigo=6522184

Gudynas, E. (2014). El posdesarrollo como crítica y el buen vivir como alternativa. En G. C. Delgado Ramos (Coord.), Buena vida, buen vivir: imaginarios alternativos para el bien común de la humanidad. (pp. 61-96). Ciudad de México, México: Universidad Nacional Autónoma de México.

Gudynas, E. y Acosta, A. (s. f.). El buen vivir o la disolución de la idea de progreso. Recuperado de www.gudynas.com/publicaciones/capitulos/GudynasAcostaDisolucionProgresoMx11r.pdf

Ibáñez, A. y Aguirre Ledezma, N. (2013). buen vivir, vivir bien: una utopía en proceso de construcción. Bogotá, Colombia: Desde abajo.

Macas, L. (2010). Sumak Kawsay: la vida en plenitud. América Latina en movimiento, 452, 14-16. Recuperado de http://www.plataformabuenvivir.com/wp-content/uploads/2012/07/ MacasSumakKawsay2010.pdf

Mamami Ramírez, P. (2011). Qamir Qamaña: dureza de "estar estando" y dulzura de "ser siendo". En I. Farah y L. Vasapollo (Coords.), Vivir bien: ¿paradigma no capitalista? (pp. 65-76), La Paz, Bolivia: Universidad Mayor de San Andrés. 
Pimentel Marañón, B. (2016). Notas sobre la solidaridad económica y la descolonización del poder. En B. Pimentel Marañón (Coord.), Políticas para la solidaridad económica y buen vivir en México. (pp. 245-282). Ciudad de México, México: Universidad Nacional Autónoma de México.

Marx, K. (1976). El capital. Tomo I: El proceso de producción del capital. Ciudad de México, México: Fondo de Cultura Económica.

Max-Neef, M. (2006). Desarrollo a escala humana: conceptos, aplicaciones y algunas reflexiones. Barcelona, España: Icaria.

Merton, R. K. (2013). Ciencia y economía en la Inglaterra del siglo XVII. En Teoría y estructura sociales. (pp. 696-713). Ciudad de México, México: Fondo de Cultura Económica.

Mignolo, W. D. (2007). La idea de América Latina: la herida colonial y la opción decolonial. Barcelona, España: Gedisa.

Pacari, N. (2009). Naturaleza y territorio desde la mirada de los pueblos indígenas. En A. Acosta y E. Martínez (Comps.), Derechos de la naturaleza: el futuro es ahora. (pp. 31-37). Quito, Ecuador: Abya Ayala.

Pachón Soto, D. (2006). Filosofía vitalista y economía solidaria. Bogotá, Colombia: Produmedios.

Pachón Soto, D. (2010). Crítica y redefinición de la categoría de progreso: hacia una "formavida orgánica”. Ciencia Política, 5(9), 131-154. Recuperado de https://dialnet.unirioja.es/ servlet/articulo?codigo $=3662577$

Pachón Soto, D. (2011). La filosofía y las entrañas: el pensar-viviente de María Zambrano. Bogotá, Colombia: Colección Nuevas Ideas.

Pachón Soto, D. (2013). Preludios filosóficos a otro mundo posible. Bogotá, Colombia: Desde abajo.

Santos, B. de S. (2010, febrero 18). Hablamos del socialismo del buen vivir. Recuperado de https://alfarcolectivo.files.wordpress.com/2011/07/hablamos-del-socialismo-del-buenvivir.pdf

Rivera, S. (2015, octubre 6). El vivir bien se transformó en una palabra hueca. Recuperado de http://www.rebelion.org/noticia.php?id=204099

Weber, M. (2004). Economía y sociedad. México, México: Fondo de Cultura Económica.

Zibechi, R. (2015). Descolonizar el pensamiento crítico y las prácticas emancipatorias. Bogotá, Colombia: Desde abajo. 